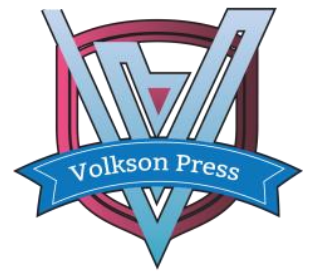

Contents List available at VOLKSON PRESS

Economics \& Management Innovations(EMI)

DOI : http://doi.org/10.26480/icemi.01.2017.83.85

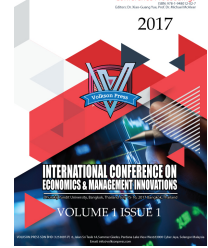

\title{
Study on Development of Cultural Tourism Industrial Clusters in Hubei Province
}

\author{
Long Minghui \\ Wuhan Donghu University, Wuhan, Hubei, China \\ 642604051@QQ.COM
}

This is an open access article distributed under the Creative Commons Attribution License, which permits unrestricted use, distribution, and reproduction in any medium, provided the original work is properly cited.

\section{ARTICLE DETAILS}

\section{Article History:}

Received 02 october 2017 Accepted 06 october 2017 Available online 11 october 2017

Keywords:

Hubei province, cultural tourism, cluster

\section{ABSTRACT}

Industrial cluster is a tightly connected spatial agglomeration body composed of a series of enterprises in varied scales and levels, multiple institutions and organizations related to their development, and other behavioral agents of a specific industry who gather in certain region and share out the work and cooperate with one another through their crisscrossed network, representing a new form of spatial economic organization standing between the market and hierarchy. It is not only the product of history and the division of labor, but also the general law in the industrialization and city planning process. Industrial cluster has been increasingly important in promoting competitive advantage of industries. Currently, industrial cluster has become a new strategy for industrial development in many countries and regions worldwide. The cultural tourism industry in Hubei Province has developed rapidly in recently years, but due to the particularity of tourism industry, the competitiveness of cultural tourism industrial cluster is affected by many factors. Based on effect and significance analysis of clusters development in Hubei cultural tourism industry, this paper puts forward ideas and countermeasures on the development of the cultural tourism industry in Hubei Province by setting up the objectives, positioning the pattern of development, and giving priority to the development of cultural tourism industrial clusters in the harmony of natural landscape and cultural tourism, integration of tourism industry and cultural industry, optimization of industrial structure, and match of different elements.

\section{Introduction}

Since the 18th National Congress of the Communist Party of China, the central government and the State Council have attached great importance to cultural construction and have issued a series of major strategic plans for cultural reform and development. Compared to the existing traditional industries, cultural tourism industry is a relatively new field. It combines tourism with the intention of appreciating traditional culture in foreign lands, pursuing cultural relics and celebrity footprints, or participating in local cultural activities, and tourism activities enabling tourists to gain rich cultural connotation and in-depth participation in tourism experience. In view of the high added value of cultural tourism industry and sustainable development, after 1970s, every country has attached increasing importance to the development of cultural tourism industry, taking measures to promote development of national cultural tourism industry, which makes it the most vigorous emerging industry in economic and social development in the new century.

As a comprehensive tourism activity with rich cultural connotation and destination the object, cultural tourism is both a periodical perception and experience of the destination's culture and an appeal and expression to the aesthetic taste and ethnic culture emotion. Cultural tourism development not only helps to protect and develop the distinctive culture of all nations and regions and enrich and improve the connotation and value of tourism products, but is conducive to promoting the transformation and development of regional economic structure. China's economy is in a convergence where some traditional supporting forces are declining, while some new forces are emerging. Some new formats and new industries are in explosive growth, among which is the cultural tourism industry. The advantage in group competition and effect in agglomeration economy of tourism industry clusters are hardly matched by other forms. Its effects in external economy, technical innovation, regional brand, and positive feedback greatly promote regional economic and social development.

2. Development Foundations and Conditions of Cultural Tourism Industrial Clusters in Hubei Province

The construction of tourism projects has been vigorously launched and tourism has become a "depression" of various capital accumulations, with the prominent characteristics of multiple large projects, wide investment areas, excellent project structures and complete investment entities. In addition to the traditional scenic projects and hotels, all capitals such as spring hotels, theme parks, tourism shopping, outward-bound sports, tourism real estate, rural tourism, forest resort, folk culture, recreation, and rehabilitation and fitness have accelerated access to other areas of tourism industry. Tourism projects are invested throughout food, housing, transportation, traveling, shopping and entertainment and other tourist areas and the upstream and downstream tourism industries. According to statistics, as of 2016, there were 1037 travel agencies in Hubei Province, of which 74 were engaged in outbound travel services, and 435 were Grade A travel agencies with 6 among the top 50 nationwide. Star hotels in the province have grown to 541 (21five-star hotels), and there were 14Star Cruises (5five-star cruises), with greatly enhanced comprehensive reception capacity. While strengthening the six elements of traditional tourism, Hubei Province vigorously expands tourism development areas and extends the tourism industrial chain, cultivating a large number of new operational types of tourism. Consequently, the tourism industry has become a complex industry of related parties. Resources of related industries are effectively integrated and new forces such as tourism equipment manufacturing, tourism commodity production and processing, tourism transportation, tourism cultural creation, tourism exhibition, tourism finance and insurance and others suddenly emerge. The tourism industry has evolved into a large complex industry with multiple categories, long chains, broad contacts and remarkable performances.

\section{Significance of Cultural Tourism Industrial Clusters in Hubei Province}

Industrial cluster is a new form of spatial organization for enterprises. It is a mutually independent and interrelated organization assembly established from specialized division of function and cooperation, and a vibrant new organization formed by informal relationship among independent enterprises. It is the effective form to realize economies of scale and economies of agglomeration. Tourism industry cluster takes tourism as the leading factor and tourism consumption demand as the driving force. While sharing the tourism infrastructure, regional brand and joint bulk procurement, tourism enterprises in a cluster can reduce operating costs or obtain additional income, and of course they can improve the production efficiency by focusing on certain part on the 
tourism industry's value chain.

\subsection{Integrate resources and enhance the capacity in development and overall planning}

The development of tourism industry cluster is to break the constraints of administrative divisions to the planning and development of tourism resources. In accordance with market principles and methods, through effective integration of industrial resources, it can achieve efficient use of resources and product (format) innovation so as to promote the development of the whole industry. Through the cluster development, it is conducive to the unified planning and overall development of tourism resources to achieve intensive development and standardized construction, and promote the creation of high-grade scenic spots. The cluster development is conducive to organically integrating the "six elements" of the tourism industry to enhance the integrality, cooperativity and systematicness of the development and openness, realizing integration of elements like tourism and culture, sports, environmental protection, and others. By exploiting the breadth, depth and thickness of tourism resources, and developing diversified format and commodity supply and services supported by demands, with the principle of survival of the fittest, cluster development will comprehensively enhance the quality, grade and level of the tourism industry.

\subsection{Improve enterprise strength and promote industrial structure optimization of tourism}

By promoting the development of tourism industry clusters with the market-oriented and entrepreneurial measures, and through the establishment of a reasonable profit distribution mechanism, it will strengthen mutually beneficial cross-region cooperation in tourism enterprises and tourism, break the administrative regime of tourism resources, and gradually straighten out the management system of scenic spots. Cluster development promotes leading tourism enterprises to be bigger and stronger, and improves the driving force and competitiveness for tourism development; it contributes to agglomeration and union of large numbers of corresponding small and medium enterprises so as to enhance the cohesion and vitality. In the environment of increasing tourism consumption, the primary task of expanding the total amount of tourism is to expand the number of tourism enterprises and effective products and services.

\subsection{Gather industries and enhance industrial contributions}

The development of industrial cluster contributes to promoting system and mechanism innovation for enterprises in a cluster, accelerating industrial capitalization and securitization with assets the bond, realizing mergers, acquisitions and optimization of enterprises, and effectively attracting social and private capital investments, gradually transforming the cluster development into a large modern enterprise group featured with mixed ownership so as to effectively enhance the vitality and motive force of development. The development of cultural tourism industrial clusters is to, in accordance with the issue of insufficient matches for cooperation of various industries in the tourism industry, develop the linkage effects of the tourism industry, construct the cultural tourism industry chain and industry cluster advantages in Hubei province, and cultivate a series of consumption hotspots and service bases.

\subsection{Upgrade the brand and expand the influence}

Unlike other brands in the primary, secondary and tertiary industries, main features of tourism industry's brand lie in the highly related format and long value chain; tourism has strong creativity. It can rely on natural resources and other tangible resources, and humanity history, legends and other intangible resources to transform the intangible culture into concrete products, and to create a travel atmosphere with the experienceoriented feature. Promote the development of tourism industry clusters. Based on cohesive development, rich industrial system, and strengthened power, industrial clusters will focus on innovating the brands, expanding the connotation of the brands, and promoting and marketing the brands, which is conducive to rapidly enhancing the brand image, infiltration and influence of a number of tourist attractions and enterprises, developing a number of well-known scenic spots and famous enterprise brands in the domestic and foreign market so as to form a brand system in tourism brands to completely promote the new advantage of brands in tourism.

\section{Measures to Promote Development of Cultural Tourism} Industrial Clusters in Hubei Province

\subsection{Adhere to planning and instruction and integrate resources}

Planning is the leader and guide of the development of tourism industry clusters. Developing without planning is blind. The development plan of tourist industry clusters should be scheduled by experts and talents according to the resources endowment, geographical location, and historical and cultural traditions. The development plan of tourism industry clusters should be connected with the local urban and rural construction planning and land use planning. The leapfrog development of tourism industry shall be driven by strengthening the integration of tourism resources and facilities, stepping up efforts to promote the cluster development of tourist attractions and tourism enterprises, and creating tourism brands with core competitiveness and major influence. We shal strengthen the resource integration, production integration and service integration between tourism and related industries, and establish the industry linkage mechanism with tourism the engine so that the new style of tourism industry will most directly drive the development of related industries.

\subsection{Cultivate leading enterprises and create the advantage of} clusters

Leading enterprises are important leaders in the development of industrial clusters. Regard the bigger and stronger leading enterprises as the priority to promote the construction of industrial clusters. Insist on the principle combining introduction and cultivation to develop and expand leading enterprises, and gradually develop and attract more relevant enterprises to be together, giving full play to its role of supporting and leading in the development of industrial clusters. Supports for leading enterprises shall be given in financing policies, tax concessions, and talent introduction.

\subsection{Boost Industrial Park construction and optimize cluster surroundings}

Industry Park is the spatial expansion and important carrier of the development of tourism industry cluster. Qualified areas should improve the industrial supporting level of the park, and actively guide tourism commodity processing enterprises, logistics enterprises, health entertainment enterprises, cultural performing enterprises and specialized markets to gather in the park. In close connection with the actual development of tourism industry in the region, a number of production centers, trading centers and information centers have been built to provide a complete public service system for the tourism industry.

\subsection{Build key projects and draw more attention}

Key project construction is an important measure to enhance the core competitiveness of industrial clusters and the development potential of tourism industry clusters. In accordance with the integration mode of "core scenic spots, tourist service base, small tourism towns, central tourism city, and rural idyllic scenery", 10 ecological tourism accumulation areas including Wuhan Commercial Leisure, Three Gorges International Resort, Shennongjia Ecological Experience, Wudang Mountains Landscape Regimen, Longzhong Cultural Leisure, Qingjiang River Ecological Folklore, Jingzhou Jing-Chu Culture, Dahong Mountain Ecological Leisure, Xianning Spa, and Dabie Mountain Red Ecology are built; led by the six 5A scenic spots in the area of "one river and two mountains", the Yangtze River scenic belt will be built to comprehensively facilitate the transformation and upgrading of leading tourism products, further promote the standardization of tourism, and actively establish the brands of urban tourism, rural tourism and tourism enterprises.

\section{Acknowledgement}

This research was financially supported by the Humanities and social science research project of Hubei Provincial Department of Education.( [2017] No.3 Document, 17G080) One of the research results of Humanities and social science research project of Hubei Provincial Department of Education "The Agglomeration of Cultural Tourism Industry in Hubei Province and the Research of its Competitiveness".

\section{References}

[1] Mclntosh. Tourism-principles, practices, philosophies [M].NY: Wiley,1977.

[2] Michael. Clusters and the new economics of competition[J].Harvard Business Review,1998(6):77-91.

[3] Yang Y. Agglomeration destiny and tourism development in China: An empirical research based on dynamic panel data model[]].Tourism Management,2013(33):1347-1359. 
[4] Arsezen-Otamisa ,\& Yuzbasionlu, N.Analysis of Antalya Tourism Cluster Perceived Performance with Structural Education Model[J].Procedia-Social and Behavioral Sciences,2013(99):682-690.

[5] Michael E.Porter. Clusters and the new economics of competition [J]. Harvard Business Review.1998,76(6)77-90.

[6] Zhao liming. Industry convergence under the perspective of Economics. Tourism Journal.2011.
[7] Balaguer J,Permias J C. Relationship between spatial agglomeration and totel prices.Evidence from business and tourism consumers[J].Tourism Management,2013,36:391-400.

[8] Pan jinghu,Li junfeng. Quantitative geographical analysis of spatial structure of A-class tourist attractions in China. Economic geography,2013 , 33(9):154-160. 